\title{
"A gente nunca pensou que teria que recomeçar": histórias de vida na extinção das fundações do Rio Grande do Sul
}

\author{
Caroline Bastos Capaverde \\ Pontifícia Universidade Católica do Rio Grande do Sul (Porto Alegre, RS, Brasil) \\ Fernanda Tarabal Lopes ${ }^{2}$ \\ Universidade Federal do Rio Grande do Sul (Porto Alegre, RS, Brasil) \\ Clara Maduell Gómez $z^{3}$ \\ Universidade Federal de Minas Gerais (Belo Horizonte, MG, Brasil) \\ Andrea Poleto Oltramari ${ }^{4}$ \\ Universidade Federal do Rio Grande do Sul (Porto Alegre, RS, Brasil) \\ Lucas Manassi Panitz $z^{5}$ \\ Universidade Federal do Rio Grande do Sul (Porto Alegre, RS, Brasil)
}

\begin{abstract}
No âmbito das políticas neoliberais, é possível localizar, na história recente do Estado do Rio Grande do Sul, gestões que aderiram fielmente a esses preceitos, como o recente governo de José Ivo Sartori (2015-2018). Essa optou por combinações de políticas de austeridade e de reformas a partir da diminuição da participação do Estado na sociedade. Nosso artigo busca refletir sobre as condições de vida e de trabalho dos servidores públicos estaduais gaúchos frente à crise e compreender como um casal de servidores engendra possibilidades de enfrentamento à precarização das relações de trabalho - produto da gestão neoliberal - que outrora estruturavam a vida familiar. A partir das histórias de vida de Maria e João, discorremos sobre a flagrante piora nas condições de trabalho, seja na infraestrutura e no remanejamento arbitrário, seja nos planos de carreira ou mesmo em suas estabilidades. Refletimos que, no âmbito da crise, há precarização da vida e na produção da subjetividade desses trabalhadores, o que desemboca na assunção de novos papéis sociais e reconfigurações relacionais na conjugalidade.
\end{abstract}

Palavras-chave: História de vida, Trabalho, Neoliberalismo, Conjugalidade.

\begin{abstract}
"We never thought we would have to start over": life stories in the extinction of foundations in Rio Grande do Sul
Within the scope of neoliberal policies, it is possible to locate, in the recent history of the State of Rio Grande do Sul, administrations that faithfully adhered to these precepts, such as the José Ivo Sartori's administration (2015-2018). This administration opted for austerity and reform policy combinations, based on the decrease of the State's participation in society. Our article seeks to reflect on the living and working conditions of the State's civil servants in the face of the crisis and to understand how a couple of civil servants engender possibilities of coping with the precariousness - a product of neoliberal management - of labor relations that once structured family life. Based on the life stories of Maria and João, we talk about the flagrant worsening in working conditions, whether in infrastructure and arbitrary relocation, in career plans or even in their stability. We reflect that, in the crisis, there is a precariousness in workers' life and production of subjectivity, which leads to the assumption of new social roles and relational configurations in conjugality.
\end{abstract}

Keywords: Life history, Work, Neoliberalism, Conjugality.

\footnotetext{
https://orcid.org/0000-0002-5019-2616

https://orcid.org/0000-0003-2920-1255

https://orcid.org/0000-0002-2883-0570

https://orcid.org/0000-0002-5897-2772

https://orcid.org/0000-0002-8429-571X
} 


\section{Reforma do Estado e aprofundamento da crise}

$\mathrm{N}_{\mathrm{r}}^{\circ}$ contexto das políticas neoliberais desencadeadas na América Latina pelos chamados primeiro e segundo Consensos de Washington (Bresser-Pereira, 2003), é possível localizar, na história recente do Rio Grande do Sul, aquelas gestões que aderiram fielmente a esses preceitos, como a recente (2015-2018), que optou por combinações de políticas de austeridade e de reformas, a partir do encolhimento da participação do Estado na sociedade via privatizações, extinções ou diminuições de funções a ele atribuídas. A narrativa das gestões neoliberais é a constante afirmação e convencimento da opinião pública de um contexto de endividamento do Estado que só seria vencido por sua própria dilapidação. As táticas de convencimento incluem, por exemplo, aliança com as mídias comerciais locais (Pasti et al., 2017) que replicam sua narrativa acriticamente, parcelamento dos salários dos servidores públicos, ameaças de aumento de impostos e, principalmente, má gestão premeditada dos serviços públicos de atendimento à população. Do ponto de vista do servidor, há flagrante piora nas condições de trabalho, seja na infraestrutura e no remanejamento arbitrário, seja nos planos de carreira ou mesmo em sua estabilidade (Santos et al., 2016).

Na gestão do Estado do Rio Grande do Sul, no período 2015-2018, podemos realçar ações emblemáticas. Em primeiro lugar, o conturbado processo de extinção das fundações estatais, no qual grande parte dos quadros pertenciam ao regime CLT. É possível dizer, com base em Tartaruga (2016, 6 de dezembro), que o fim das fundações promove a extinção de boa parte da inteligência técnico-científica do poder público e da possibilidade de desenvolvimento econômico e social do Estado por meio da inovação e da tecnologia. Em segundo lugar, destacamos a diminuição da infraestrutura do Estado tratada como passivo econômico. Em terceiro lugar, elencamos as privatizações, com o pretexto de pagar a dívida do Estado, dos bancos e das companhias de energia, saneamento e mineração.

É nesse contexto que se insere o presente trabalho. As histórias, que por ora apresentamos, retratam a realidade de um casal de servidores públicos que vivenciou, em seu cotidiano, as transformações decorrentes da extinção das organizações em que atuavam: a Fundação de Economia e Estatística do Rio Grande do Sul - FEE, e a TV Educativa de Porto Alegre - TVE. Trata-se da apresentação de duas histórias - a de Maria e a de João (nomes fictícios) - que nos auxiliam a refletir sobre as condições de vida e de trabalho dos servidores públicos estaduais gaúchos frente à crise do Estado. Nosso esforço objetiva compreender como ambos celetistas, com mais de vinte anos de trabalho nessas fundações, engendram possibilidades de enfrentamento à desordem postulada pela dinâmica das políticas neoliberais e a precarização das relações de trabalho "estáveis" - que até então alicerçavam a dinâmica da vida familiar. Há muita discussão em torno da crise no RS no âmbito político, econômico e social; nosso objetivo é integrar a discussão, buscando dar visibilidade às histórias dos sujeitos trabalhadores e como esses experimentam a situação da crise.

A pesquisa em história de vida é o caminho de destaque considerado em nossa investigação. O uso de dados biográficos na pesquisa científica é amplo e perpassa diversas áreas do conhecimento. Nos amparamos na perspectiva da Psicossociologia ou Sociologia Clínica, na qual a história de vida se apresenta como material privilegiado para pesquisa (Barros \& Lopes, 2014). A pesquisa em história de vida consiste na busca do conhecimento a partir da experiência do sujeito, recolocando-o no social e na história. Por esse caminho, prioriza-se a relação entre o indivíduo e a sociedade, estabelecendo vínculos entre aspectos globais e particulares, e destacando as complexas relações entre as condições de vida e o vivido.

Para tanto, esse estudo se organiza em outras cinco seções: apresentamos mais elementos relativos ao quadro de extinção das fundações no RS, o contexto específico da Fundação de Economia e Estatística (FEE) e da Fundação Piratini - da qual a TVE faz parte; discutimos sobre as metamorfoses do trabalho no contexto do neoliberalismo; apresentamos e debatemos sobre as histórias de vida dos sujeitos em questão e, por fim, à guisa de conclusão, refletimos sobre o Estado do Rio Grande do Sul em seu atual estágio de precarizações neoliberais. 


\section{A extinção das fundações no Rio Grande do Sul}

Foi aprovado no dia 21 de dezembro de 2016, por 30 votos a 23, o Projeto de Lei no 246/2016 do Poder Executivo do Rio Grande do Sul que autorizou a extinção de seis fundações de direito privado da administração pública indireta. A justificativa anunciada pelo Poder Executivo para proposição da medida é a continuidade das reformas na estrutura da Administração Pública do Estado, diminuindo as despesas e os custos do Estado.

As fundações incluídas no projeto eram: Fundação Zoobotânica do Rio Grande do Sul, Fundação de Ciência e Tecnologia - CIENTEC, Fundação de Economia e Estatística Siegfried Emanuel Heuser - FEE, Fundação Piratini, Fundação para o Desenvolvimento de Recursos Humanos - FDRH e Fundação Estadual de Planejamento Metropolitano e Regional METROPLAN. Durante o processo de extinção, havia promessa de que os empregados do quadro de pessoal teriam seus contratos de trabalho rescindidos, no prazo de até 180 dias, com o pagamento das rescisões conforme a legislação trabalhista.

No dia 17 de janeiro de 2017, foi sancionada a Lei no. 14.982 (2017), que autoriza a extinção de fundações de direito privado do Estado e, no mesmo dia, foi instituída a Comissão Especial para acompanhamento e monitoramento das atividades relativas às extinções de órgãos públicos por meio do Decreto no. 53.404/2017 (2017): "O grupo, que deve trabalhar pelos próximos 180 dias, terá a responsabilidade de acompanhar os atos legais e administrativos e realizar todas as ações necessárias para o cumprimento do previsto nos projetos de lei que foram sancionados" (“Governo Encaminha", 2017).

Para este trabalho, é relevante ressaltar as características da FEE e da TVE, locais de expediente do casal estudado. A Fundação de Economia e Estatística - FEE, criada em 13 de novembro de 1973, realiza estudos e pesquisas de temas de desenvolvimento econômico, social e institucional. É (era) a maior fonte de dados estatísticos sobre o RS, dispondo de importante acervo de informações, pesquisas e documentos de natureza socioeconômica. O Estado alega que os serviços de avaliação econômica e estatística que servem de base para os seus programas passarão a ser executados por um departamento na Secretaria de Planejamento, Governança e Gestão. Então, os funcionários da FEE serão desligados, já que possuem vínculo empregatício regido pela CLT; exceto os 52 empregados estabilizados (Governo do Estado do RS, 2016).

Já a Fundação Piratini, criada em 31 de dezembro de 1980, é gestora das emissoras públicas de televisão e rádio do Estado do RS - TVE e FM Cultura. Produz e transmite programas educativos, culturais e jornalísticos. A justificativa do governo é que não haveria extinção das emissoras públicas de rádio e televisão, a concessão de ambas seguirá em vigor. O Estado alega que o atual modelo não consegue acompanhar a evolução tecnológica e demais avanços do setor. A estrutura e as atividades hoje desenvolvidas pela Fundação, em processo de extinção, serão assumidas pela Secretaria de Comunicação, encarregada de criar um novo modelo de gestão. Os funcionários igualmente serão desligados, uma vez que possuem vínculo empregatício regido pela CLT (Governo do Estado do RS, 2016). Sobre o quadro da extinção das fundações no Estado do Rio Grande do Sul, o que se observa na atualidade é, mesmo após alguns embates judiciais, o prosseguimento desse processo.

Em que pese o desmonte da administração pública no Rio Grande do Sul, há que se considerar que os efeitos recaem diretamente tanto nos usuários, pela falta do serviço e atendimento, quanto nos servidores públicos, que têm, em suas trajetórias, anos de dedicação ao trabalho que, em pouco tempo, veem desmoronar.

\section{Metamorfoses do trabalho no contexto do neoliberalismo}

O trabalho segue como categoria central do sistema capitalista, e não podemos negar a importância que sempre teve na vida das pessoas, também por seu significado simbólico. Antunes e Alves (2004) colocam que o trabalho, em compreensão ampliada, pode ser relacionado com: 
a totalidade dos assalariados, homens e mulheres que vivem da venda da sua força de trabalho, não se restringindo aos trabalhadores manuais diretos, incorporando também a totalidade do trabalho social, a totalidade do trabalho coletivo que vende sua força de trabalho como mercadoria em troca de salário (Antunes \& Alves, 2004, p. 342).

Dejours (2004, p. 28) diz que trabalho "é aquilo que implica, do ponto de vista humano, o fato de trabalhar: gestos, saber-fazer, um engajamento do corpo, a mobilização da inteligência, a capacidade de refletir, de interpretar e de reagir às situações; é o poder de sentir, de pensar e de inventar etc". Consideramos, com essa lente, que o trabalho é um elemento central em nossa base social; ser cidadão/ã está atrelado a ter uma ocupação produtiva que gere renda.

Na sociedade capitalista, na qual o consumo dita os modos de vida, esse é o meio de satisfação das necessidades humanas, de constituição do sujeito e de sua rede de significados e sua independência financeira. Disso decorre que trabalho pode influenciar a autoconsciência e a liberdade dos indivíduos na tomada de decisões, visto que os produtos de sua atividade funcional são capazes de concretizar suas próprias escolhas (Barroco, 2001).

Segundo Rosenfield e Almeida (2014), o trabalho, especialmente o trabalho assalariado, constituiu-se historicamente como via de acesso a direitos; o/a trabalhador/a acessava proteção oriunda de sua inserção laboral. Então, o trabalho é uma atividade fundamental para o desenvolvimento do ser humano e também é uma forma de pertencimento social. Nessa linha, Coutinho et al. (2007) explicam o trabalho como categoria estrutural da vida em sociedade. $O$ trabalho tem uma fundamental dimensão na vida do ser humano e está implicado, além da garantia da satisfação das necessidades básicas, na constituição das identidades individuais e coletivas, e nas formas de sociabilidade.

A produção da subjetividade do ser humano contemporâneo está, assim, cada vez mais atrelada à função simbólica do trabalho. E, nesse sentido, para Dejours (2004), o trabalho não pode ser quantificado e o seu reconhecimento passa pelo exercício da visibilidade da atividade, especialmente advinda dos pares. Dessa forma, o autor ressalta a importância da coletividade e da solidariedade como estratégias de defesa frente ao processo de desestruturação e constrangimentos advindos do mundo do trabalho. Nesse sentido, para o autor: "trabalhar não é tão somente produzir: trabalhar é ainda viver junto. Viver junto não é produto de geração espontânea; pressupõe uma atenção em relação ao outro" (Dejours, 2004, p. 18).

As últimas décadas do século XX foram alvos de diversas transformações em diferentes esferas da sociedade, inclusive na estrutura socioeconômica e produtiva do capitalismo que trouxe novas roupagens ideológicas e políticas marcadas pela competitividade, eficiência e lucratividade. O emprego de políticas neoliberais aumenta o caráter financeiro da economia sobre o produtivo. Privatizações e a liberalização do mercado passam a ser o lema das novas políticas econômicas. Essas mudanças nos níveis de investimento e na flexibilização no mercado de trabalho afetam significativamente os setores econômicos, agora desregulamentados, alterando também as estruturas ocupacionais.

Dessa forma, fica evidente que a precarização e a flexibilização das relações de trabalho são elementos comuns nessa nova fase do capitalismo. Antunes e Alves (2004) defendem que a metamorfose do trabalho "insere-se em um contexto de mundialização do capital". Na conjuntura neoliberal, a mundialização do capital ou a economia capitalista mundial é caracterizada pelo desemprego estrutural, pela redução e precarização das condições de trabalho (Antunes \& Alves, 2004) e tem assumido um papel importante nos ideais de progresso e de desenvolvimento das nações.

As novas exigências do sistema têm impacto notável, ainda mais na vida de servidores que estão sob sujeição do Estado, agora considerados um entrave ao desenvolvimento do próprio. O governo do Estado do Rio Grande do Sul adere a essas práticas neoliberais que sucateiam o serviço público e precarizam em demasia o trabalho dos servidores do Estado e é até mesmo nocivo para a saúde desses trabalhadores.

Segundo Antunes e Alves (2004), na era da globalização e da mundialização do capital, a classe trabalhadora é fragmentada, heterogênea e diversificada. O sistema, sob controle do capital, tornou o trabalho ainda mais precarizado, com uma perda significativa de direitos e de 
sentidos por meio das formas de subempregos, desempregos e intensificando os níveis de exploração para os trabalhadores.

A classe trabalhadora, atualmente, compreende a totalidade dos assalariados; homens e mulheres que vivem da venda da sua força de trabalho e que são despossuídos dos meios de produção. Ela vem sofrendo alterações, presenciando um processo multiforme.

Então, o processo de precarização emerge de uma crise estrutural do capital e de grandes mudanças no mundo do trabalho. No contexto do capitalismo mundializado dado pela reestruturação produtiva e transnacionalização do capital há principais tendências para essa mudança: a redução do proletariado industrial tradicional e especializado que dá lugar a formas mais desregulamentadas de trabalho, reduzindo fortemente o conjunto de trabalhadores estáveis que se estruturavam por meio de empregos formais; aumento do novo proletariado fabril e de serviços, os terceirizados, presente nas diversas modalidades de trabalho precarizado; aumento significativo do trabalho feminino, ainda que os níveis de remuneração das mulheres são, em média, inferiores àqueles recebidos pelos homens, o mesmo ocorrendo com relação aos direitos sociais e do trabalho, que também são desiguais; expansão dos assalariados médios no "setor de serviços", que inicialmente incorporou parcelas significativas de trabalhadores expulsos do mundo produtivo industrial como resultado do amplo processo de reestruturação produtiva, das políticas neoliberais e do cenário de desindustrialização e privatização; crescente exclusão dos jovens que atingiram a idade de ingresso no mercado de trabalho e dos trabalhadores considerados "idosos" pelo capital, com idade próxima de 40 anos e que, uma vez excluídos, dificilmente conseguem reingresso no mercado de trabalho. Ambos, sem perspectiva de emprego, acabam muitas vezes engrossando as fileiras dos trabalhos precários, dos desempregados dada a vigência da sociedade do desemprego estrutural; crescente expansão das vagas no chamado "terceiro setor", assumindo uma forma alternativa de ocupação, que vem incorporando trabalhadores expulsos do mercado de trabalho formal e passam a desenvolver atividades não lucrativas, não mercantis, reintegrando-os. Também ocorre o crescimento do trabalho em domicílio, permitida pela desconcentração do processo produtivo e pela expansão de pequenas e médias unidades produtivas.

A configuração do mundo do trabalho é cada vez mais transnacional. Assim, nessa reconfiguração, tanto do espaço quanto do tempo de produção, algumas regiões industriais desaparecem, enquanto novas emergem e paulatinamente inserem-se no mercado mundial. Há um complexo processo de ampliação das fronteiras no interior do mundo do trabalho.

Assim, segundo Antunes e Alves (2004), este é o cenário diverso e heterogêneo que caracteriza a nova estrutura da classe trabalhadora: além das clivagens identitárias entre os trabalhadores, temos também as estratificações e fragmentações que se acentuam em função do processo crescente de internacionalização do capital. Como todo trabalho produtivo é assalariado, mas nem todo trabalhador assalariado é produtivo, essa nova noção mais complexificada de classe trabalhadora deve incorporar a totalidade dos(as) trabalhadores(as) assalariados(as).

Para o autor, é preciso levar em conta que hoje, particularmente na América Latina, presenciamos, nos estratos mais penalizados pela precarização do emprego, o estranhamento e o fetichismo capitalista que são diretamente mais desumanizadores e bárbaros em suas formas de vigência (Antunes \& Alves, 2004). A precarização possui essa essência desigual e, segundo Lima e Oliveira Neto (2017), no caso brasileiro, a experiência de precarização é decorrente da insegurança social que desponta num contexto histórico específico: a hegemonia neoliberal.

De modo geral, hoje, no Brasil, há falta de oportunidades de emprego. Em dezembro de 2018, o Instituto Brasileiro de Geografia e Estatística (IBGE, 2018) divulgou dados da Pesquisa Nacional por Amostra de Domicílios Contínua (Pnad Contínua) com a seguinte mensagem: "falta emprego para mais de 27 milhões de brasileiros". Essa carência está diretamente associada à crescente exclusão social e à elevação dos níveis de pobreza. Há, também, uma insegurança por parte da população que se agravou com a Reforma Trabalhista proposta em 2017. Nos governos neoliberais, se acentuam a precarização do trabalho, o fim do referencial do emprego, a flexibilização das leis e do trabalho, a crescente informalidade e proliferação dos "bicos". 
Podemos somar a isso o cenário de terceirizações, privatizações e de destituição de direitos que produzem graves efeitos sobre a saúde mental do trabalhador. Se alinharmos essa concepção ao contexto de dissolução das fundações públicas, podemos inferir que as decisões da gestão atual do Estado têm implicações diretas na carreira dos servidores públicos com consequências no âmbito familiar desses trabalhadores.

Presenciamos, então, um processo histórico de desintegração que se direciona para o crescimento do antagonismo e das contradições do capital. Quando se pensa na massa de desempregados, as formas de absolutização da alienação são diferenciadas como: rejeição da vida social, isolamento, apatia e silêncio até violência e agressão diretas.

Dejours (2004) ainda chama a atenção para a rapidez das mudanças no mundo do trabalho desde a transformação no perfil da classe trabalhadora aos avanços tecnológicos e organizacionais, muitas vezes sem o acompanhamento cognitivo dessas mudanças, "criando um processo de desqualificação permanente do trabalhador, do seu saber-fazer e de sua experiência acumulada" (Dejours, 2004, p. 26).

Dessa forma, a revolta dos que foram expulsos do mundo do trabalho, impedidos de ter uma vida dotada de algum sentido, se manifesta de várias formas. A desumanização segregadora leva ao isolamento individual, à formação de guetos de setores excluídos, às formas de criminalidade e até a formas mais ousadas de explosão social. Notamos, com isso, como "a alienação/estranhamento e os novos fetichismos que permeiam o mundo do trabalho tendem a impedir a autodeterminação da personalidade e a multiplicidade de suas qualidades e atividades" (Antunes \& Alves 2004, p. 349). A vida dos atuais trabalhadores é cercada de inseguranças, incertezas e falta de garantias socioeconômicas. Isso posto, podemos refletir até que ponto o Estado (soçobrado em contradições) está cumprindo seu papel enquanto instância reguladora e provedora de mecanismos de apoio ao trabalhador, intervindo e assumindo responsabilidades que possam garantir a redução do sentimento de desamparo, emergente na contemporaneidade.

Concomitantemente às mudanças no mundo do trabalho, os mecanismos de proteção e fiscalização da saúde do trabalhador encontram-se deteriorados, corroendo as possibilidades de zelar por sua subjetividade. A partir do momento em que se retira a chance de as pessoas construírem suas vidas, suas relações afetivas pelo trabalho, se suprime também a construção da identidade pelo trabalho.

Com o exposto, sugerimos que o trabalho ocupa um papel central na vida das pessoas, seja no processo de socialização, seja no processo de subjetivação do trabalhador. E podemos perceber, junto a isso, que a constituição desse novo padrão de acumulação flexível vem se caracterizando pela acentuação da precarização do trabalho. E, nesse contexto e diante do processo de globalização, torna-se essencial a regulação do mercado de trabalho para que se possa reduzir o emprego precário e incorporar uma forma mais ampla com políticas públicas eficazes (Lima \& Oliveira Neto, 2017). Nesse sentido, o papel e atuação do Estado enquanto regulador do processo de trabalho tem implicações no desenvolvimento humano por meio do trabalho.

\section{História de vida de um casal diante do processo de extinção das fundações}

Procedemos a uma análise da trajetória profissional do casal no setor público, a partir da narrativa do par, considerando o contexto da extinção das instituições públicas em que trabalham. Optamos pelo método da história de vida que "implica uma produção de conhecimento baseada no discurso do sujeito sobre sua situação concreta de vida, construído na experiência cotidiana e na interlocução" (Araújo et al., 2010, p. 140).

O uso do método biográfico na pesquisa científica é amplo e perpassa por diversas áreas do conhecimento. Neste estudo, destacamos a abordagem oriunda do campo da Psicossociologia (Barros \& Silva, 2002; Barros \& Lopes, 2014; Bosi, 2003; Ferrarotti, 1990; Gaulejac, 1996, 2005), no qual a história se apresenta enquanto material privilegiado de pesquisa. Outra característica importante a ser ressaltada, nessa perspectiva e enquanto potencialidade do 
método, refere-se à ponte, à ligação, entre o social e o individual, entre objetivo e subjetivo, entre mundo psíquico e mundo social, que a metodologia nos permite. $\mathrm{O}$ material produzido pelas histórias de vida expressa as determinações sociais nas trajetórias individuais e a relação dos atores com essas determinações. Também permite compreender a relação entre o indivíduo produto da história e o indivíduo agente da historicidade (Gaulejac, 2005).

A relação entre o sujeito e o social se faz de forma dialética: o homem determina a sociedade e ao mesmo tempo é determinado por ela. Ao se abordar sobre história de vida, é fundamental admitir a ideia de uma subjetividade ativa e transformadora, mas que ao mesmo tempo se constrói numa base material e histórica de existência. Afinal, a história expressa uma vivência individual, singular, que perpassa, transformando e sendo transformada pela condição sócio-histórica concreta. Dessa forma, é trabalho da investigação descobrir, nas determinações de cada narrativa, sua pergunta específica e sua universalidade (Dubet, 1996). Ferraroti (1990) aborda sobre a "dialética do social" que consiste na complexa relação entre as condições de vida e o vivido. Ou seja, devemos ter em mente que a biografia individual se encontra numa relação dialética com a situação histórica datada e vivida. Reconhecer a influência do social é fundamental para o trabalho com histórias de vida.

Outro ponto importante a ressaltar refere-se às dinâmicas estabelecidas entre aquele que pesquisa e o sujeito sobre o qual se conta. Para Ferraroti (1990), nos relatos de história de vida, a situação clínica é vivida no modo mágico e mítico da comunicação. Segundo o autor, há um polo clínico no relato biográfico que se relaciona à hermenêutica de uma interação. A situação clínica vislumbrada no recolhimento de história de vida remonta àquela que se coloca na relação paciente-terapeuta, o que revela importante faceta deste método: a relação ao outro. Ferraroti (1990) destaca que essa relação não se dá por um encontro entre um sujeito ativo (pesquisador) e um objeto passivo (pesquisado), "mas antes como um casal no qual os dois parceiros jogam com papéis alternados". A constatação do autor reforça a importância da transferência na relação entre o pesquisador e o sujeito que narra sua história.

A escolha, então, do método da história de vida para analisar o processo de extinção das fundações em que trabalham, a partir da análise da rotina profissional e pessoal do casal, alinhase à singularidade dessa experiência, que é "individual e única, pois trata da história de um indivíduo particular a partir da sua perspectiva e à luz da sua experiência, portanto imbuída da subjetividade do narrador" (Brandão, 2007, p. 1).

Maria, 50 anos, e João, 48, estão casados há 20 anos, sem filhos. Colegas de faculdade, namoraram por dois anos antes do casamento. E, a partir daqui, descreveremos elementos desta história atravessada pela dissolução das fundações públicas.

Antes disso, no entanto, podemos perguntar: Como chegamos até o casal? Os(as) pesquisadores(as) passaram a participar, a partir de interesse primeiro no tema das dissoluções das fundações públicas no Estado do RS, de manifestações e encontros que ocorriam nos espaços públicos da capital gaúcha, na cidade de Porto Alegre. Durante esses primeiros contatos, produzimos diários de campo, para mapear os temas emergentes junto à experiência ora vivenciada pelos servidores/funcionários públicos que integravam esses coletivos. A partir de conversas informais com esses atores, passamos a nos aproximar de algumas histórias que iam caracterizando, dia a dia, o que estava sendo vivenciado pelos servidores, suas histórias e os diálogos que estabeleciam com pares e com os demais atores representantes políticos e sindicais. A partir desta interação com o campo, conhecemos João e Maria, por isso convidamos cada um a descrever, mais pormenorizadamente, suas histórias e agendamos a primeira entrevista (separadamente) com o casal.

Para o recolhimento das histórias, realizamos seis encontros com os sujeitos. Nos reunimos com Maria por duas vezes em seu ambiente de trabalho e uma vez no ambiente da universidade. Também falamos com João em seu local de trabalho. Posteriormente, ocorreram duas visitas ao apartamento onde moram, com um intervalo de um mês. Cada ocasião durou, aproximadamente, duas horas, e foram conduzidas por um roteiro previamente semiestruturado que continha as seguintes orientações: conte sua trajetória de vida e trabalho e como iniciou sua 
atividade na Fundação; conte como o casal enfrentou a notícia de extinção das fundações; como os gestores comunicaram e como os colegas reagiram a essa notícia.

\section{Maria}

Formada em Ciências Contábeis e Administração. Entrou na FEE na condição de estagiária. Em 1990, fez concurso nível médio para a Fundação e foi selecionada. À época, pensou que o ingresso no serviço público seria apenas uma primeira fase de sua vida profissional, entretanto, não foi assim. Ela narra:

Eu conheci a FEE através de uma pessoa e fui trabalhar como estagiária na parte administrativa em 88, eu acho. Enquanto eu cursava Administração, e a minha ideia a princípio era voltar pra Torres ..., o governo do Pedro Simon autorizou o primeiro concurso público porque as pessoas já estavam ficando mais antigas e eles precisavam de gente nova, então eles fizeram concurso, tinha lá umas 15 ou 20 vagas ... eu estudei lá dentro nas horas vagas e o pessoal incentivava. Então, minha história foi assim sendo construída, como se fosse assim minha família, como se fosse eu crescendo dentro da minha família. Quando eu fiz estágio eu tinha 17, quando eu passei eu tinha 23 pra 24 anos, pra mim era por um tempo, aí eu fui ficando (Maria).

Em 2017, completou 26 anos de trabalho no mesmo local. Maria relata que, desde então, o trabalho na instituição passou por várias modificações, alavancadas pela Revolução Tecnológica, bem como por mudanças econômicas, sociais e políticas, as quais engendram novas formas de trabalho na Fundação. Os avanços tecnológicos, segundo Maria, ampliaram as pesquisas e os meios de publicizar os estudos estatísticos e econômicos do Estado do RS. Ao mesmo tempo, com a escassez de novos concursos, o grupo de pesquisadores e colaboradores administrativos da FEE tornou-se unido e próximo, caracterizando a ambiência laboral uma extensão da própria família: "As pessoas sempre foram muito amigas, meus amigos de vida estão aqui na FEE". A união do grupo refletia na qualidade do serviço, pois o ambiente sempre foi de qualidade reconhecida por todos, evidenciando o que Dejours (2004) refere como o reconhecimento do trabalho pelos pares.

Com relação à vulnerabilidade da Fundação, Maria resgata: "Nas trocas de governo, sempre tivemos muito medo, pois as fundações sempre foram muito vulneráveis". Mas afirma que a crise da Instituição se agravou após o governo Rigotto, segundo ela:

Paralisou praticamente o Estado, a gente não produzia nada, então ali a gente começou a sentir que a crise estava se formando, ali começou o perigo dessa coisa de "Vocês não são necessários para o Estado", então a gente tinha isso em mente: que um dia eles podiam achar que a pesquisa não fosse necessária (Maria).

Na percepção de Maria, isso ocorre principalmente porque apesar de a FEE ter convênios com várias universidades e contribuir com a educação, fornecendo dados atualizados sobre o Estado e sobre o país, auxiliando também para o desenvolvimento de políticas públicas, existem partidos que não dão muita importância aos dados. Isso fica claro ao assumir o governo José Ivo Sartori. Conforme Maria: "A visão do governo era de que tinha essa coisa que a FEE era muito voltada para academia, que eles não podiam pagar algo assim, que era um luxo para o Estado. Então, a ideia era essa ... diminuir". Em que pese sobre o desconhecimento do trabalho do outro, Dejours (2004) aponta para possíveis momentos de desencadeamento de sofrimento no trabalho, uma vez que pela gestão lhe é associada a invisibilidade do seu trabalho.

Com a saída do presidente da FEE em julho de 2016 e a consequente não nomeação do próximo, Maria e seus colegas passaram a questionar o futuro do órgão. $\mathrm{O}$ mais paradoxal para ela é que o sentimento de incerteza sobre o futuro profissional incitado pela inexistência de um Presidente para a Instituição, somado ao "burburinho" relacionado à possível extinção das fundações no Estado do RS, emergiu em um momento em que a FEE estava com uma demanda de trabalho excessiva, voltada a construir dados para o governo, como salário mínimo e outras informações para a Secretaria Geral de Governo. Maria relembra: 
De forma direta, jamais foram sinceros conosco, ficamos sabendo por meio da imprensa que tinha uma boa relação conosco. Quando meus colegas souberam sobre a extinção ser real, eu estava de férias e recebi uma mensagem que dizia: "O gato subiu no telhado", comecei a chorar imediatamente. Pelo meu processo de trabalho, por várias vezes me imaginei fazendo a demissão dos meus colegas, fazendo as contas, foi desesperador (Maria).

Nesse ponto, Maria chama à cena, novamente, a união do grupo de colegas:

Ao saber, em uma sexta-feira, que a FEE entraria no pacote da extinção, o pessoal da comunicação trabalhou no final de semana. Lançamos uma página para comunicar sobre a importância do trabalho realizado aqui e montamos grupos de discussões no WhatsApp para seguir cada passo do projeto de extinção que seria lançado pelo Governo (Maria).

Nessa altura, segundo ela, surgiram sentimentos de raiva, desesperança, esperança, desespero, e também horas de luta em grupo:

E aí a gente ficou naquela luta um mês . . . um mês de sofrimento, eu não conseguia comer . . . a única parte boa foi que eu emagreci cinco quilos. Eu só tinha olhos, sentimentos e cabeça pr'aquilo ... eu tirei alguns dias de férias e fui visitar uma amiga em Florianópolis . . . foi a pior coisa que eu fiz na minha vida porque eles criaram um grupo no WhatsApp e ficavam debatendo ali ... essa casa da minha amiga era em Ribeirão da Ilha, quase não pegava a internet . . . ela mora na beira do mar, eu olhava aquilo e não tinha nada que me alegrasse, era uma angústia. A coisa que eu mais lembro era de manhã, quando eu abria os olhos, eu imaginava que uma pessoa muito próxima morreu numa tragédia e tu abre os olhos e vê que aquilo é verdade, então essa sensação eu tinha sempre, tanto que eu fui-me embora antes, pra ficar com o pessoal ... parece que aquilo era um conforto, a gente tá junto na mesma luta, nem que fosse pra sofrer estando próximo, porque sofrer distante é muito complicado. . . . Então, durante o tempo de luta, passamos por diversas manifestações, debates, que nos alimentavam a esperança. Era um dia bom, outro, ruim. E assim fomos indo, durante a longa jornada até percebermos que não teria saída. Mas participar do momento de luta foi importante para que tomássemos consciência da situação. Vestimos, juntos, a camiseta ... Percebi que quem estava há mais tempo, sofreu ainda mais (Maria).

Para Maria, o mais difícil de compreender, durante esse processo, era a perda da estabilidade. Como empregada pública, organizou a vida financeira do casal, fez investimentos, contando sempre com o salário no final do mês, o qual, segundo ela, durante 26 anos, foi depositado em dia, o que trazia certa tranquilidade financeira.

Sobre isso, ela coloca: "Eu sempre planejei a minha vida pensando no salário. Eu já estava, na verdade, pensando na aposentadoria". Com o encerramento das atividades da Fundação, teve que repensar sobre sua vida. Ela relata: "Comecei a fazer contas lógicas, a primeira coisa que eu fiz foi uma tabela dos gastos, ver o que eu podia cortar e foi indo ... a primeira coisa que cortei foi a faxineira". Quando pensava no futuro profissional, sempre chorava: "Com a certeza da demissão, bateu o desespero e eu só pensava no que seria da minha vida. Eu caminhava na rua e chorava". As decisões relativas ao corte de gastos acabam recaindo em mulheres, inclusive, em mulheres mais vulneráveis, compondo assim uma cadeia de vulnerabilidade social. Mas, o que deixava tudo ainda mais complexo para Maria era o fato de não estar passando por isso sozinha. Seu marido, também empregado público, experimentava a mesma realidade em outra instituição pública, a TVE/RS. Ela narra:

Na verdade, eu estava com meu marido junto, que é da TVE, mas no começo ele não sentiu tanto, não sentiu como eu assim . . . eu acho que ele estava na negativa, ele não tinha essa coisa assim ... só dizia: "Não tem o que fazer, é só esperar" . . . Eu não conseguia rir . . . eu lembro que o João via uns programas de TV e ria e eu falava: "Como tu consegue achar graça de alguma coisa?", "O que eu vou fazer?" Ele me respondia . . . homem tem outra forma de lidar, acho que ele meio que atrasou um pouco, agora ele anda mais estressado com o que está acontecendo lá. Eu tinha vontade de sacudir ele, não acreditava que ele estava achando graça ... Todos os dias de manhã eu tinha a mesma sensação quando eu abria os olhos . . . parecia que eu tinha uma coisa que me prendia na cama, uma tristeza de não saber o dia de amanhã, um sufoco, que eu não 
ia conseguir respirar ... todo dia eu tinha essa sensação ... quando eu ia pra cama pra dormir, fechava os olhos pra dormir, eu já sabia como ia acordar no outro dia nesse pós ali ... porque foi uma época de muita indecisão (Maria).

Ela resume: "Se você acha que toda essa situação já é cruel o bastante para eu compreender, pense que meu marido, meu porto seguro, passava pela mesma experiência, ao mesmo tempo. As coisas fugiram do nosso controle".

\section{João}

João, formado em Ciências Contábeis, primeiro trabalhou com auditoria externa, passando por cerca de três empresas. Mais tarde, em 1996, fez concurso para a TVE e, desde então, passou a trabalhar como contador na área administrativa. Com relação à notícia de extinção, João relata:

A rotina na TV mudou bastante. Depois, agora com essa "coisa" realmente da extinção, ficamos apreensivos nessa parte profissional e também na parte pessoal, do casal, uma vez que nós dois estamos igualmente passando por isso: anseios, expectativas com relação ao futuro (João).

João reconhece que a permanência da TVE sempre foi mais frágil do que as demais fundações, tanto pelo alto custo de manutenção quanto pela representação social e política da cultura em nossa sociedade: "Sempre fomos perseguidos pelo governo. Talvez considerados supérfluos porque é a cultura. Também é uma coisa muito cara manter uma TV e uma rádio. A renovação tecnológica é onerosa”.

Apesar disso, ele não esconde sua surpresa e decepção com a concretização da extinção. A frustração de João deve-se também ao fato de ter buscado mais capacitação para aprimoramento da função, uma vez que almejava continuar na TVE até sua aposentadoria:

Já estava pensando mais na aposentadoria do que iniciar um novo trabalho. No ano passado, fiz uma pós na minha área, baseado no plano de cargos e salários, para evoluir na minha carreira, dentro do serviço público . . . Vou levar isso pra onde? E os avanços no salário? Tudo perdido (João).

A notícia da extinção foi desanimadora, pois ele percebeu, por trabalhar na área administrativa, que até mesmo o orçamento já tinha um prazo final:

Nosso orçamento para o ano de 2017 somente foi liberado por oito meses. Entendemos, assim, que até agosto isso [extinção] tem que estar resolvido. A gente não sabe o que vai acontecer, fica a dúvida. Vamos permanecer ou ser demitidos nesse dia? As pessoas se desmotivaram para trabalhar. Muitos já estão saindo, com sorte alguns passaram em outros concursos, outros procuraram a iniciativa privada (João).

João relembra que, ao contrário de Maria, não encontrou união, tampouco luta coletiva no espaço social do seu trabalho. Ele não compreende bem por que isso ocorreu, mas atribuiu à falta de entrosamento do grupo, bem como às diferentes profissões e processos de trabalho presentes na dinâmica institucional:

Lá na TVE não tem essa união do coletivo, como observado na FEE. Como são diferentes profissionais, radialistas, jornalistas e, nós, no administrativo, senti um grupo mais desunido. Também pode ser pelo fato de a maioria ser cargo de confiança. Os sindicatos são diferentes, não é a mesma integração. No entanto, com os protestos, o pessoal se uniu um pouco mais, mas não tenho essa ideia do coletivo muito forte (João).

Por essa razão, foi no casamento, e nos colegas da esposa, que João encontrou amparo para compreender o processo de extinção do trabalho: "Você fica 20 anos trabalhando, você 
ganha avanços, teu salário vai crescendo. Se fôssemos fazer concurso hoje, teríamos perda eu, então, decidi ir para rua, mas fui juntamente com o pessoal da FEE".

\section{O casal}

Com relação à experiência da demissão no ambiente conjugal, João relata que, para o futuro próximo, ambos já pensavam na aposentadoria, talvez morar fora do país, pagavam previdência privada para um futuro mais confortável, ou seja, a vida a dois sempre foi calculada e planejada: "Nossa formação em administração fez com que observássemos a vida privada também com muita organização e planejamento para o futuro". Ela adiciona:

A gente sempre teve uma organização, ainda os dois trabalhando na área financeira, agora não temos mais. Não sabemos como vai ser no ano que vem. Estamos pensando em tudo. Fizemos uma previdência privada para a gente se aposentar e ter conforto. Agora, a primeira coisa que fizemos foi suspender o pagamento. Penso: será que vou poder manter a minha casa? (Maria).

Maria afirma que decidiram não ter filhos para a manutenção de uma qualidade de vida financeira que eles consideravam adequada à vida a dois, o que agora perdia o sentido central por outras razões:

Pensamos que seria melhor investir na gente, ter uma vida confortável, viajar, do que investir em um filho. Nunca foi demais, mas também nunca foi de menos. Sempre pensamos em algum negócio para melhorar a renda, mas pensamos no tempo. Aí, de repente, o plano B tornou-se realidade. Era distante, agora é necessidade. Antes tínhamos a subsistência garantida (Maria).

Maria lembra que, à medida que ficou sabendo da extinção da FEE, a rotina do casal se transformou, tanto nas atividades corriqueiras, como ir ao supermercado, como no compartilhamento do sofrimento com tamanha complexidade de mudança não esperada na vida profissional de ambos. A mudança no trabalho também refletiu na harmonia conjugal, sensação predominante nos quase vinte anos de união, relembra Maria:

Comecei a pensar em vender tudo. Parei de me arrumar e tinha pavor de sair na rua. Comecei a tomar um ansiolítico. Eu só tinha vontade de chorar. Foi um choque para mim, os meus quase 30 anos de trabalho estavam sendo tirados de mim. Comecei a parar de gastar. Eu nunca choro, tenho horror a chorar. Passei a chorar todos os dias. Na minha cabeça era só tragédia. Chegava em casa e questionava como poderia pagar o condomínio de onde moro, falava isso com ele. Desde final de novembro (2016) até agora, janeiro (2017), eu somente vivi isso. Teve um dia que tentei ir viajar, mas foi horrível, só conseguia pensar nisso. E voltei e fui para praça, eu ia para praça todos os dias. Eu quase enlouqueci e enlouquecia ele também (Maria).

Apesar disso, também reconhecem um ponto positivo por viverem a mesma situação ao mesmo tempo, pois sentiam que havia uma compreensão mais genuína por parte do outro: "Tinha uma coisa boa, a gente sofria junto, vivia aquilo ali junto, senti o casamento de verdade quando consegui me abrir com ela, externar o que estava sentindo", conta João. Maria também retorna ao mesmo momento e resume: "Cheguei em casa, no último dia, e abracei o João e choramos abraçados, foi a primeira vez que ele chorou".

Quanto à necessidade de dar início a uma nova vida profissional, João diz: "A gente nunca pensou em ter que recomeçar, ou [pensar] em outro serviço, ser empreendedor, por exemplo". Nesse ponto, Maria relembra que os dois participaram de algumas palestras no Serviço Brasileiro de Apoio às Micro e Pequenas Empresas - SEBRAE sobre empreendedorismo e começaram a cogitar um negócio para sobreviverem. Em todas as saídas pensadas conjuntamente para o futuro profissional, a incerteza prevalece. Do empreendedorismo a deixar o país, ficar longe da família, dos amigos, foram inquietações que emergiram diante das transformações que estavam se consolidando na vida a dois. Pondera Maria: 
Começamos a pensar em ir morar fora do país. A irmã dele mora nos Estados Unidos. Mas comecei a pensar na minha vida, nas relações que construí na minha vida. Pensei na minha mãe e no meu pai, sou filha única. Então você percebe como o trabalho é central na vida. Com a ideia da extinção, você tem o relacionamento afetado, nunca choramos juntos em 18 anos de casamento, você pensa em todas as outras relações, muito difícil (Maria).

\section{Das singularidades das experiências ao vivido social: as histórias de Maria e João em contexto}

Os relatos de Maria e João demonstram, a partir das singularidades de cada trajetória e também da experiência vivenciada conjuntamente pelo casal, os processos de precarização que se acirram no serviço público gaúcho. Nossa proposta aqui foi desnudar as consequências do processo de extinção das fundações públicas no Rio Grande do Sul a partir da realidade conjugal de um casal, com o intuito de mostrar mais intimamente uma, dentre tantas pessoas e famílias que foram/estão sendo diretamente atingidas pela dissolução das instituições nas quais trabalham.

Ao apresentarmos as histórias de Maria e João buscamos dar visibilidade às singularidades do fenômeno social, econômico e político de grande amplitude e de incontáveis consequências. Refletir acerca da realidade de um casal e as múltiplas transformações de cunho íntimo, profissional decorrentes das mutações do mundo do trabalho é uma forma de reverberar narrativas que acabam ficando invisíveis por trás dos números da demissão em massa.

João e Maria, casados há quase 20 anos, identificados com o trabalho no setor público, felizes com a proximidade da aposentadoria, estão passando por múltiplas transformações não somente no trabalho, mas também na estrutura do casamento. Disso decorre que desafios inéditos para a vida a dois passaram a fazer parte da rotina conjugal oriundos, principalmente, da transformação de sua relação com o trabalho. Retomamos também que a interrupção da venda da força de trabalho como mercadoria para o setor público enseja não somente dificuldades de reconhecimento social e profissional, formação subjetiva, remanescentes da centralidade do significado simbólico daquele trabalho, mas também implica, paradoxalmente, projetar novos desafios profissionais em campo desconhecido - o privado.

Podemos ressaltar o fato de o casal ter sido desvinculado dos seus espaços de resistência, como sindicatos e associações, forçando-o a uma individualidade, incerteza e desamparo jurídicoassistencial. Assim, observamos que a precariedade dos empregos causa também a precariedade subjetiva - que gera impactos na saúde dos trabalhadores e em suas famílias - e social, já que é uma forma de exclusão. Importante pautar sobre as estratégias coletivas de defesa, estudadas por Dejours (2004), e que se apresentam como essenciais para preservar a saúde mental no trabalho, em que pese o movimento mútuo e coletivo entre os trabalhadores face ao movimento de precarização e dissolução do trabalho, tão em voga no modelo neoliberal que vem se apresentando no Brasil.

Sobre as precarizações relacionadas ao modelo neoliberal, destacamos também, na história de Maria e João, as incertezas e inseguranças que os mesmos se viram expostos a partir do "descaso do Estado" para com seus servidores. O Estado, que deveria atuar enquanto instância protetiva, de regulação e apoio aos trabalhadores, comporta-se de maneira contrária, "pelo abandono. Tal abandono repercute em Maria e João em diversos aspectos"; por um lado, são nítidas as perdas de referências identitárias e das demais significações relacionadas ao trabalho, conforme já comentado. Como destaca Clot (2006), o trabalho não é uma atividade dentre tantas outras, na medida em que se diferencia pela centralidade que ocupa na vida do sujeito, adquirindo uma função psicológica. $\mathrm{O}$ trabalho configura-se como uma das principais dimensões da vida da pessoa. Interfere em sua inserção na sociedade, delimita espaços de mobilidade social e aparece como um dos fatores constitutivos da identidade dos indivíduos. Nas histórias narradas, 
é nítida a perda de tais referenciais e os consequentes impactos na saúde mental e subjetividade de Maria e João.

"A situação de abandono e negligência por parte do Estado também repercute claramente nas dimensões materiais da existência dos narradores". Sobre esse ponto destacamos a necessidade da "reinvenção forçada da carreira" e da busca, por exemplo, por saídas como o "empreendedorismo", conforme nos conta João: "a gente nunca pensou em ter que recomeçar, ou [pensar] em outro serviço, ser empreendedor, por exemplo". Antunes e Alves (2004) destaca que no atual estágio do desenvolvimento do capital o que se observa são perdas progressivas nos direitos dos trabalhadores e perdas de postos de trabalho, que vêm acompanhadas do crescimento de subempregos e de maiores níveis de exploração. Nesse contexto, também se destacam os processos de responsabilização do trabalhador por sua empregabilidade e os processos da empresarização de si, situação na qual "questões como a do desemprego e a do aperfeiçoamento profissional convertem-se em um problema do trabalhador, não mais do Estado nem das empresas" (Andrade, 2011).

Sobre o atual estágio neoliberal do desenvolvimento capitalista e o consequente Estado de precarizações decorrentes, é necessário, a partir de nossa discussão, localizá-lo também no contexto da recente situação do Estado do Rio Grande do Sul. Além da visibilidade às histórias em questão, conforme já destacamos, cabe novamente mencionar que a abordagem da pesquisa biográfica não se encerra na riqueza das singularidades da vida narrada; a investigação com histórias de vida busca, a partir das dimensões concretas de cada experiência, constituir uma ponte do individual ao social/coletivo, de modo a estabelecer vínculos entre aspectos particulares e aspectos globais mais amplos (Lopes, 2013). Esse é o esforço que dedicamos ao próximo capítulo, à guisa de conclusão.

\section{À guisa de conclusão: o Estado sul-rio-grandense em debate}

A saída privatista dada para a crise econômica do Rio Grande do Sul pode ser mais bem compreendida em uma perspectiva de escalas, que entrelaça fatores globais, nacionais e regionais. Primeiramente, é necessário considerarmos os chamados ajustes espaço-temporais do capitalismo; esses buscam a produção de "novas divisões territoriais de trabalho, novos complexos de recursos e novas regiões como espaços dinâmicos de acumulação do capital" (Harvey, 2017, p. 144).

Em segundo lugar, consideramos as contribuições de Ruckert (2012), que visualiza o Rio Grande do Sul como um território de internacionalização segmentada do espaço nacional - isto é, um contexto no qual o Estado, para atender às demandas nacionais de integração com os países vizinhos, se fragmenta e se reestrutura para se consolidar como Núcleo Geoeconômico do Mercosul - um corredor que se desenvolve de São Paulo à Buenos Aires. Consideramos que esse novo papel, iniciado nos anos 1990, coloca o território estadual na mira dos interesses corporativos internacionais, como no caso das commodities agrícolas e florestais.

Por fim, na escala regional, vemos um discurso sistemático da mídia local, dos representantes do capital financeiro e de parte da classe política, na direção da dilapidação do patrimônio estatal como única saída para a resolução da crise financeira. Por certo, neste discurso jazem interesses não só internacionais, mas também da iniciativa privada nacional e regional que deseja ampliar sua participação na prestação de serviços para a esfera pública. Fato concreto foi, às vésperas da extinção da FEE, a contratação pelo governo do Estado de uma empresa privada para realizar uma pesquisa realizada há anos por essa Fundação, sob o valor de 3,3 milhões de reais. Esse único serviço equivalia à época a praticamente o orçamento de dois anos da FEE. Tal fato, também comentado por Maria em uma de nossas entrevistas, leva-nos a inquirir se o real motivo da extinção de tal Fundação se deu por motivações orçamentárias (Jacobsen, 2018).

É importante notar que o Rio Grande do Sul se posiciona de maneira muito distinta de outros Estados, como São Paulo. A exemplo, destacamos o papel preponderante de duas fundações. A FAPESP (Fundação de Amparo à Pesquisa do Estado de São Paulo) que é regida 
por lei estadual que destina parte do PIB de São Paulo à educação e pesquisa; sua robustez orçamentária é o que tem levado as universidades estaduais paulistas a liderarem os melhores rankings de pesquisa científica no Brasil e se destacarem no cenário global. A Fundação Padre Anchieta, responsável pela TV e Rádio Cultura, reestrutura-se ao longo do tempo e a cada nova gestão, sem deixar de ser pública e de alcançar protagonismo nacional. Esses exemplos marcam a importância da pesquisa científica e da comunicação social como política pública e como estratégia de desenvolvimento no espaço nacional. Ao contrário, o Rio Grande do Sul tem preterido essas duas áreas reiteradamente, por meio da extinção, restrição orçamentária e precarização do trabalho de órgãos de pesquisa e planejamento como a Fundação Zoobotânica (FZB), Fundação de Amparo à Pesquisa (FAPERGS), Fundação Estadual de Planejamento Metropolitano e Regional, além das já comentadas ao longo deste trabalho.

Resgatar a dimensão da reestruturação neoliberal do Estado do Rio Grande do Sul é essencial para a compreensão e para a contextualização das histórias narradas. O caso de Maria e João nos evidencia que tal reestruturação vem acompanhada de experiências e dramáticas singulares no rol de seus servidores públicos e que necessitam ser visibilizadas.

A pesquisa também nos aponta que a problemática em questão é complexa, e que para seu profundo entendimento faz-se fundamental os diálogos, visões e compreensões interdisciplinares; intentamos ter contribuído também nesse sentido. Por fim, ressaltamos a importância de nosso estudo enquanto instrumento de denúncia, e que deve ser ampliado ao contexto brasileiro; apesar de anunciarmos a cena de uma localidade específica, temos ciência de que as precarizações, direcionamentos e transformações relacionadas ao contexto neoliberal na administração pública que por ora apresentamos não se restringem ao sul do Brasil.

\section{Referências}

Andrade, D. P. (2011). Empresa Humana ou Humano Empresa? GV-executivo, 10(1), 38-41. https://doi.org/10.12660/gvexec.v10n1.2011.22943

Antunes, R. \& Alves, G. (2004). As mutações no mundo do trabalho na era da mundialização do capital. Educação ES Sociedade, 25(87), 335-351. https://doi.org/10.1590/S0101-73302004000200003

Araújo, A. D. G., Nogueira, M. L. M., \& de Barros, V. A. (2010). Histórias de vida e trabalho cultural: a construção do sujeito e a pertinência da memória. Cadernos CERU, 21(2), 139-151. https://www.revistas.usp.br/ceru/article/view/11921

Barroco. M. L. S. (2001). Ética e serviço social: fundamentos ontológicos. Cortez.

Barros, V. \& Lopes, F. T. (2014). Considerações sobre a pesquisa em história de vida. In Eloisio M. de Souza (Org.), Metodologias e analíticas qualitativas em pesquisa organizacional: uma abordagem teórico-conceitual (pp. 41-63). EdUFES.

Barros, V. A. \& Silva, L. R. D. (2002). A pesquisa em história de vida. In I. B. Goulart (Org.), Psicologia organizacional e do trabalho: teoria, pesquisa e temas correlatos (pp. 133-146). Casa do Psicólogo.

Bosi, E. (2003). O tempo vivo da memória: ensaios de psicologia social. Ateliê.

Brandão, A. M. (2007). Entre a vida vivida e a vida contada: a história de vida como material primário de investigação sociológica. $\quad$ RepositóriUM, 83-106. https://repositorium.sdum.uminho.pt/bitstream/1822/9630/3/Entre\%20a\%20Vida\%20Vivida\%20(2).pdf

Bresser-Pereira, L. (2003). O segundo consenso de Washington e a quase estagnação da economia brasileira. Revista de Economia Política, 23(3), 343-375. https://doi.org/10.1590/0101-31572004-0665

Clot, Y. (2006). A função psicológica do trabalho. Vozes.

Coutinho, M., Krawulski, E., \& Soares, D. (2007). Identidade e Trabalho na contemporaneidade: repensando articulações possíveis. Psicologia Eु Sociedade, 19(nspe.), 29-37. 
Decreto no 53.404, de 16 de janeiro de 2017 (2017). Institui Comissão Especial para acompanhamento e monitoramento das atividades inerentes às extinções de entidades integrantes da Administração Pública Indireta http://www.al.rs.gov.br/legis/M010/M0100099.asp?Hid_Tipo=TEXTO\&Hid_TodasNormas=63674\&hTe $\mathrm{xto}=\&$ Hid_IDNorma $=63674$

Dejours, C. (2004). Addendum. Da psicopatologia à psicodinâmica do trabalho. In S. Lancman \& L. Sznelwar (Orgs.), Christophe Dejours: da psicopatologia à psicodinâmica do trabalho (pp. 49-106). Fiocruz.

Dubet, F. (1996). Sociologia da experiência. Instituto Piaget.

Dubet, F. (1998). L'expérience sociale et les conditions d'une sociologie clinique. Les cahiers du laboratoire de changement social, 3, 9-16.

Ferrarotti, F. (1990). Histoire et histoires de vie. Méridiens Klincksieck.

Gaulejac, V. (1996). Histoires de vie et choix théoriques. Les Cahiers du Laboratoire de Changement Social, 1, 15-27.

Gaulejac, V. (2005). Historia e historicidad. In V. Gaulejac, S. R. Márquez, \& E. T. Ruiz (Eds.), História de vida: psicoanálisis y sociología clínica (pp. 61-90). Universidad Autónoma de Querétaro.

Governo encaminha ações para efetivação do Plano de Modernização do Estado. (2017, 18 janeiro). govrs novas façanhas. https://estado.rs.gov.br/governo-encaminha-acoes-para-efetivacao-do-plano-de-modernizacaodo-estado

Governo do Estado do Rio Grande do Sul. (2016). Reestruturação do Estado. Novembro de 2016. http://www.novoEstado.rs.gov.br/arquivos

Harvey, D. (2017). 17 contradições e o fim do capitalismo. Boitempo Editorial.

Instituto Brasileiro de Geografia e Estatística (2018). Pnad-Contínua.

Jacobsen, G. (2018, 8 maio). Terceirização e medida que impede demissão de empregados da FEE geram duplicidade de gastos para o governo do RS. Zero Hora (Caderno Política). https:/gauchazh.clicrbs.com.br/politica/noticia/2018/05/terceirizacao-e-medida-que-impede-demissao-deempregados-da-fee-geram-duplicidade-de-gastos-para-o-governo-do-rs-cjgy4m13306mz01qob5f876ic.html

Lei n⿳ำ 14.982, de 16 de janeiro de 2017. (2017). Autoriza a extinção de fundações de direito privado da Administração Pública Indireta do Estado do Rio Grande do Sul e dá outras providências. http://www.al.rs.gov.br/filerepository/repLegis/arquivos/LEI\%2014.982.pdf

Lima, E. C. \& Oliveira Neto, C. R. (2017). Precarização do trabalho no contexto da reestruturação produtiva $\begin{array}{llll}\text { brasileira. Revista } & \text { Espaço } & \text { 9cadêmico, }\end{array}$ https://periodicos.uem.br/ojs/index.php/EspacoAcademico/article/view/32911

Lopes, F. T. (2013) Entre o prazer e o sofrimento: histórias de vida, drogas e trabalhos. [Tese de Doutorado em Administração, Universidade Federal de Minas Gerais].

Pasti, A., Bandeira, O., Gallas, L., Fonseca, D., Valente, J., Cornils, P., Urupá, M., \& Steenfadt, O. (2017). Quem controla a mídia no Brasil? MOM-Brasil (Midia Ownership Monitor). https://brazil.mom-rsf.org/br/

Projeto de Lei n⿳o 246/2016, Autoriza a extinção de fundações de direito privado da Administração Pública Indireta do Estado do Rio Grande do Sul e dá outras providências. http://proweb.procergs.com.br/Diario/DA20161206-01-100000/EX20161206-01-100000-PL-246-2016.pdf

Rosenfield, C. L. \& Almeida, M. L. (2015). Contratualização das relações de trabalho: embaralhando conceitos canônicos da sociologia do trabalho. Revista de Ciências Sociais, Política Ė Trabalho, 2(41). https://periodicos.ufpb.br/ojs/index.php/politicaetrabalho/article/view/21219 
Ruckert, A. A. (2012). O Rio Grande do Sul como um território de internacionalização segmentada do espaço nacional. In R. Verdum, L. A. Basso, \& D. M. A. Suertegaray (Orgs.), Rio Grande do Sul: paisagens e territórios em transformação (pp. 313-328). EdUFRGS.

Santos, R., Gomes, F., Santos, T., Ribeiro, E., \& Andrade, L. (2016). A crise, o Estado e os equívocos da administração política do capitalismo contemporâneo. Cadernos EBAPE.BR, 14(4), 1011-1034.

Senado Federal. (2017). Consolidação das leis do trabalho - CLT e normas correlatas. Senado Federal. https://www2.senado.leg.br/bdsf/bitstream/handle/id/535468/clt_e_normas_correlatas_1ed.pdf

Tartaruga, I. (2016, 6 de dezembro). As fundações gaúchas são importantes para o desenvolvimento de inovações tecnológicas no Estado? Sul 21 (Opinião). https://sul21.com.br/opiniao/2016/12/as-fundacoes-gauchas-saoimportantes-para-o-desenvolvimento-de-inovacoes-tecnologicas-no-estado-por-ivan-g-peyre-tartaruga/

\section{E-mail para correspondência ccapaverde@gmail.com}

Recebido em: 08/07/2020

Revisado em: 04/08/2021

Aprovado em: 06/08/2021 